\title{
Dieter Heckmann (dir.), avec la collaboration de Krzysztof Kwiatkowski, Das Elbinger Kriegsbuch (1383-1409). Rechnungen für städtische Aufgebote
}

Köln, Weimar, Wien : Böhlau (Veröffentlichungen aus den Archiven Preußischer Kulturbesitz, 68), 2013, 436 p., 54,90

Mathieu Olivier

\section{(2) OpenEdition} Journals

Édition électronique

URL : http://journals.openedition.org/ifha/7550

DOI : $10.4000 /$ ifha. 7550

ISSN : 2198-8943

Éditeur

IFRA - Institut franco-allemand (sciences historiques et sociales)

Référence électronique

Mathieu Olivier, «Dieter Heckmann (dir.), avec la collaboration de Krzysztof Kwiatkowski, Das Elbinger Kriegsbuch (1383-1409). Rechnungen für städtische Aufgebote », Revue de l'IFHA [En ligne], Date de recension, mis en ligne le 13 décembre 2013, consulté le 22 septembre 2020. URL : http:// journals.openedition.org/ifha/7550 ; DOI : https://doi.org/10.4000/ifha.7550

Ce document a été généré automatiquement le 22 septembre 2020.

(CIFHA 


\section{Dieter Heckmann (dir.), avec la collaboration de Krzysztof Kwiatkowski, Das Elbinger Kriegsbuch (1383-1409). Rechnungen für städtische Aufgebote}

Köln, Weimar, Wien : Böhlau (Veröffentlichungen aus den Archiven Preußischer Kulturbesitz, 68), 2013, 436 p., 54,90

\section{Mathieu Olivier}

La multiplication des éditions de sources portant, au sens le plus large du terme, sur l'histoire militaire de la Prusse médiévale, a donné une nouvelle impulsion à un domaine de recherches qui passait naguère encore pour démodé ; il n'est pas exagéré de dire qu'elle a profondément renouvelé la vision classique des "guerres de l'ordre Teutonique " aux XIV et $\mathrm{XV}^{\mathrm{e}}$ siècles, notamment pour la période critique de part et d'autre de la célèbre bataille de Tannenberg (1410). Modèle de coopération scientifique germano-polonaise, le présent volume s'inscrit dans cette dynamique éditoriale et pose un jalon supplémentaire pour une meilleure appréhension de la chose militaire dans l'Europe du Centre-Est à la fin du Moyen Âge. Le document en question est un registre ou, pour mieux dire, un livre de comptes élaboré au tournant du XIVe et du XV siècle dans l'une des principales cités marchandes de Prusse, Elbing (pol. Elbląg), et conservé aujourd'hui dans les fonds des Archives d'État de la ville de Gdańsk. Document comptable de facture assez classique - les éditeurs insistent à juste titre sur ce point dans leur introduction - jusque dans son aspect général et sa disposition typographique, le «Livre des guerres" se singularise pourtant par son contenu: les scribes du Conseil de Ville y consignèrent année après année, sur une période de près de trente ans, la composition des contingents urbains tenus de participer aux différentes opérations militaires, de caractère offensif ou défensif, conduites sous l'égide des chevaliers teutoniques, maîtres du pays. L'ouvrage comprend trois parties 
distinctes. Une longue introduction procure au lecteur tout ce qu'il est en droit d'attendre en pareil cas: description très minutieuse du document, du support, identification des deux mains à l'œuvre dans le manuscrit, nécessaires éclaircissements sur le modus operandi d'un document qui, à première vue, se présente sous la forme d'une litanie de noms assez cryptique, et brève tour d'horizon des campagnes militaires elbingeoises. Suit le texte de l'édition lui-même, si fidèle au manuscrit que l'on serait fondé à parler d'édition diplomatique. Il est prolongé par un impressionnant répertoire prosopographique de plus de 200 pages. Chacun des noms cité dans le «Livre des guerres " y a sa notice, longue de quelques lignes ou de plus de deux pages (!) en fonction de la plus ou moins grande profusion des informations fournies par les sources éditées et inédites. L'auteur de ces lignes, qui connaît assez bien la richesse des fonds berlinois et dantzickois, avoue son admiration béate pour ce travail proprement titanesque (et passablement ingrat), mené en l'espace de quelques années seulement, et tout à fait comparable à celui auquel dut s'atteler Sven Ekdahl pour le Livre des soldes de l'ordre Teutonique (voir Revue IFHA, $\mathrm{n}^{\circ} 4$ ). Rendu intégralement pour la toute première fois, parfaitement décrypté et analysé, le « Livre des guerres » d'Elbing fera le bonheur de nombreux historiens, au-delà même des spécialistes de la Prusse médiévale et de l'ordre Teutonique. Les historiens des infrastructures de la guerre à la fin du Moyen Âge seront confrontés à une pièce archivistique qui a peu d'équivalents, en tout cas dans les pays germaniques; ceux qui s'intéressent à l'histoire des sociétés urbaines sur le pourtour de la Baltique au temps de la splendeur hanséatique y trouveront également un matériau abondant. Un seul petit regret: pourquoi avoir relégué l'ensemble de l'apparat critique après le texte lui-même (p. 201-202) ? L'ouvrage n'en est pas moins une très belle réussite, et un véritable modèle pour l'édition de textes $d u$ même genre.

\section{INDEX}

Index chronologique : Mittelalter

Thèmes : Militärgeschichte

\section{AUTEUR}

\section{MATHIEU OLIVIER}

Lycée Dumont-d'Urville, Toulon 